\title{
Body Mass Index
}

\section{Obesity, BMI, and Health: A Critical Review}

\author{
Frank Q. Nuttall, MD, PhD
}

The body mass index (BMI) is the metric currently in use for defining anthropometric height/weight characteristics in adults and for classifying (categorizing) them into groups. The common interpretation is that it represents an index of an individual's fatness. It also is widely used as a risk factor for the development of or the prevalence of several health issues. In addition, it is widely used in determining public health policies. The BMI has been useful in populationbased studies by virtue of its wide acceptance in defining specific categories of body mass as a health issue. However, it is increasingly clear that BMI is a rather poor indicator of percent of body fat. Importantly, the BMI also does not capture information on the mass of fat in different body sites. The latter is related not only to untoward health issues but to social issues as well. Lastly, current evidence indicates there is a wide range of BMls over which mortality risk is modest, and this is age related. All of these issues are discussed in this brief review. Nutr Today. 2015;50(3):117-128

$\mathrm{B}$ ody fatness has been an important psychosocial issue among humans for millennia. It is clearly manifested by paleolithic statuettes of exceedingly plump women. This suggests being "full figured" was highly desirable at least for women. In contrast, images of obese people, males or females, are never exhibited in ancient Egyptian funerary wall paintings, stellae, or statues suggesting that fatness was not considered to be a desirable trait there. This also is the case in artifacts from other cultures in the Middle East in that era. Why the degree of fatness has varied in different cultures is not clear. However, it may have depended on the availability of a reliable food supply and the effort required in obtaining it.

Frank Q. Nuttall, MD, PhD, is a full professor at the University of Minnesota, Minneapolis, and chief of the Endocrine, Metabolic and Nutrition Section at the Minneapolis VA Medical Center, Minnesota. His PhD degree is in biochemistry. He has more than 250 scientific publications in peer-reviewed journals, and he is the winner of numerous prestigious academic and scientific awards, including the 2014 Physician/Clinician Award of the American Diabetes Association.

The author has no conflicts of interest to disclose.

Correspondence: Frank Q. Nuttall, MD, PhD, Minneapolis VA Medical Center, One Veterans Dr 111G, Minneapolis, MN 55417 (Nutta001@umn.edu).

This is an open-access article distributed under the terms of the Creative Commons Attribution-NonCommercial-NoDerivatives 3.0 License, where it is permissible to download and share the work provided it is properly cited. The work cannot be changed in any way or used commercially.

DOI: 10.1097/NT.0000000000000092
More recently, the degree of rotundity considered ideal also has varied considerably in the general population, but particularly for young women. Before the 1920s, "full figured" women were considered to be desirable as long as the distribution was hourglass in type. However, the 1920s Flapper era introduced abbreviated and revealing dresses. The result was that thinness was not only desirable but also required. This concept has moderated but still influences women's views of beauty and eating habits at present.

\section{Fatness as a Personal or Society Issue}

Traditionally, a person's fatness has been defined at a personal level as well as at a societal level. However, this is difficult to quantify. That is, each individual has his/her own perception of how fat he/she should be. As indicated above, this often depends on a general concept of societal norms or is due to peer pressure. For example, currently in Western societies, young women are often concerned about their body image, and most consider themselves to be too fat, even though they are well within population-based references. This is not only due to societal concepts of an ideal degree of fatness, but also due to thinness being a goal promulgated by the fashion industry and reinforced by commercial advertising. At a societal level, although poorly described or quantified, there also is a degree of fatness beyond which a person generally is considered to be unacceptably fat; that is, there is an ill-defined threshold at which a person is labeled as being "fat" or "obese." However, it is based on the "I can't define it but I know it when I see it" concept. In addition, implicit in this context is that the location of the excess fat plays a role, as does a person's age. It is much more acceptable to be "overweight" when one is old than when one is young. Also particularly in women, the accumulation of fat in certain areas of the body is considered to be much more acceptable than in other areas. For example, truncal (belly fat) accumulation would be considered to be less acceptable than the accumulation of fat in the peripelvic and thigh areas as well as in the breast area ${ }^{1}$; that is, one may be statistically "fat" but with an appropriate figure be merely referred to "as amply endowed" or "pleasingly plump."

The social consequences of being "too fat" are severe. Discrimination begins in childhood and results in serious emotional scars. Societal discrimination limits career choices, and indeed many career paths are closed to those considered to be too fat. Also, societal stigmatization often impairs a person's ability to express his/her intellectual and other talents; that is, they become underachievers. In addition, the 
potential pool of mates is limited because of their perceived unattractiveness. Thus, obese people tend to marry other obese people and, parenthetically, to produce obese children. ${ }^{2-4}$

\section{Fatness as a Medical Issue}

Not only the societal but also the functional and indirectly the medical consequences of an excessive accumulation of fat also have been recognized for millennia. Nevertheless, the concept that "body build" (fatness) is a major populationbased medical issue gained popularity in this country only shortly before 1900. Life insurance data accumulated at that time ${ }^{5}$ and subsequently ${ }^{6}$ indicated that body weight, adjusted for height (Wt/Ht), was an independent determinant of life expectancy, and in 1910, the effects of being overweight were noted to be greater for younger people than for the elderly. ${ }^{6}$

Subsequently, the Metropolitan Life Insurance Company in 1959 published tables of average body weights for heights (Wt/Ht) by gender and at different ages. ${ }^{7}$ This was based on data from 1935 to 1953 from more than 4 million adults, mostly men, insured by 26 different insurance companies. The risk for development of certain diseases as well as mortality data related to $\mathrm{Wt} / \mathrm{Ht}$ differences also were analyzed and reported in the 1960 Statistical Bulletin of the Metropolitan Life Insurance Co. ${ }^{8,9}$

The Wt/Ht tables were used for many years as a reference for population-based studies. If a person's Wt/Ht was 20\% above or below the mean for that height category, he/she was considered to be overweight or underweight, respectively. The insurance data also indicated the ratios of weights for heights (the term used was "body build") at which mortality was lowest in adults. The latter was referred to as the "ideal" or later the "desirable" weight. All of these data were periodically updated. ${ }^{10}$ Interestingly, from 1959 to 1983, the desirable weight, that is, the weight/ height representing the lowest mortality had increased. ${ }^{10-12}$ However, a "desirable body" weight for height was invariably lower than the average weight for height in the insured population. ${ }^{7,10,13}$

\section{Problems With the Wt/Ht (Body Build) Index}

Early on it was recognized that tall people had a lower death rate than did short people $7,8,13$ with the same Wt/Ht ratio. It also was recognized that a person's height in general and leg length in particular could affect the calculated body mass adjusted for height. A person's bony frame, that is, bone mass, also could affect the interpretation of this ratio. In general, it reflected whether one was narrowly or broadly built. Thus, efforts were made to eliminate lower limb length and frame size as variables. ${ }^{7,10}$ The strategy was to develop representations of body build, that is, charts of weight/height that were independent of these variables. The overall goal was to have the same distribution of $\mathrm{Wt} / \mathrm{Ht}$ at each level of height.
Although not stated, the implicit goal in developing these tables was to define a person's fat mass as a proportion of their total mass, irrespective of their height or frame size. ${ }^{14}$ Efforts were made to adjust for frame size (nonfat mass) by categorizing people as those with a small, medium, or large frame. Estimation of frame size was attempted using a number of measurements including shoulder width, elbow width, knee width, ankle width, and so on. ${ }^{15}$ None of these were widely adopted. Nevertheless, frame size based on elbow width was included in the Metropolitan Life weight/ height tables, ${ }^{7,10}$ even though it was never validated.

\section{Mathematical Adjustment of Body Build}

Mathematically, the issue of adjusting body build for differences in height was approached with the concept that the body, particularly the trunk, could be considered as being a 3-dimensional volume or mass. Thus if a tall person were simply a scaled-up version of a short person, weight would increase approximately with the cube of height. ${ }^{16}$ Indeed, several equations were developed and tested based on this concept; that is, the cube root of weight divided by height $(3 \sqrt{\mathrm{Wt}} / \mathrm{Ht})$ or weight/ height, ${ }^{3}$ and so on, but none were ideal. ${ }^{17}$ This is because tall people are not just scaled-up versions of short people. As indicated previously, they tend to be more narrowly built resulting in a greater lean/fat proportion of body mass.

Later, it was shown that the body mass for height actually scaled best with weight for height when the height was raised to the 1.6 to 1.7 exponent (Wt/Ht, ${ }^{1.6}$ etc). ${ }^{18}$ Thus, with an increase in $\mathrm{Ht}$, the effect of $\mathrm{Ht}$ on the ratio is exponential, whereas the change in Wt is linear. This has the effect of $\mathrm{Ht}$ on the ratio to be magnified as Ht increases. Overall, it results in a lower ratio in tall people than will be obtained with just a Wt/Ht ratio. Thus, it potentially compensates for a narrower build in tall compared with short people.

This exponent is not convenient for use in populationbased studies, and it was determined that $\mathrm{Wt} / \mathrm{Ht}^{2}$ generally was satisfactory. ${ }^{16,18}$ The latter represents the Quetelet Index. It was developed by Dr Quetelet in the 1800s.

\section{Lambert Adolph Jacque Quetelet}

I would like to briefly mention who Dr Quetelet was and how the "Quetelet Index" was derived. ${ }^{19-21}$ Lambert Adolphe Jacque Quetelet (1796-1874) was a Flemish astronomer and statistician. Indeed, he is considered to be the patriarch of statisticians. He introduced the concept of "social averages." In developing the "social average" concept, his goal was to determine the characteristics of an "average man" and the distribution of various human characteristics around the "average man." Overall, it was his desire to obtain a distribution such that it formed a bell-shaped curve, that is, a Gaussian or normal distribution. He referred to his studies as "social physics." Thus, this represents the first application of distribution mathematics to human characteristics. In 1835, Quetelet noted the body mass relationship 


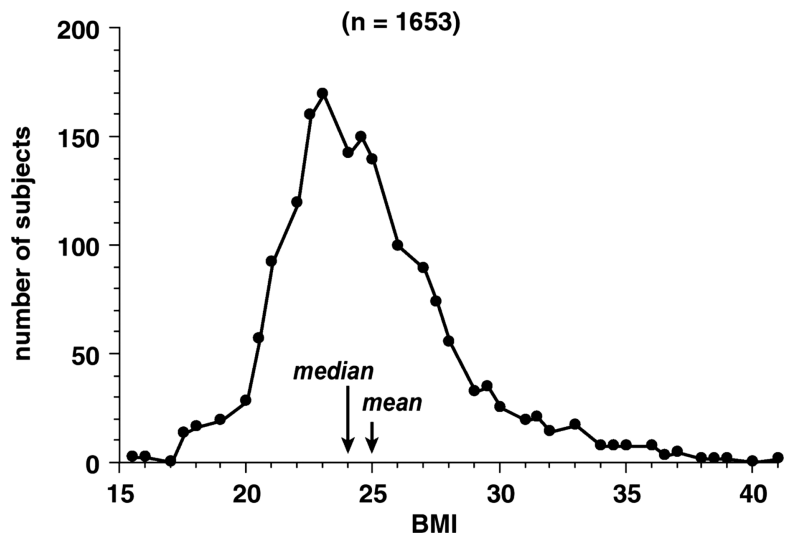

FIGURE. Distribution of BMI in Adult American Men and Women (Carnegie Institute of Washington, Publ No 329. 1923). Adapted from Rony. 27, p192

to height in normal young adults was least affected by height when the ratio of weight to height squared was used rather than merely using the ratio of the weight to height or weight to height raised to the third power. ${ }^{16}$

\section{Adoption of the BMI as an Index of Obesity}

In 1972 , Keys et $\mathrm{al}^{16}$ severely criticized the validity of Metropolitan Life Insurance published data per se, and the then-published tables of desirable weight for height, as well as the tables used to define people who were underweight or overweight. ${ }^{7}$ (The pejorative term "obese" was rarely used in that era.) Instead, Keys et al, using better documented weight for height data, popularized the Quetelet Index in population-based studies. They referred to it as the body mass index (BMI). Thus, Quetelet Index = body weight (kilograms) divided by height squared (meters) $=$ BMI. As indicated above, by squaring the height, it reduces the contribution of leg length in the equation and tends to normalize the body mass distribution at each level of height; that is, it reduces the effect of a variance in height in the relationship of weight to height. This was considered to be important because most of body fat is in the trunk. Nevertheless, as also pointed out by Keys et al, ${ }^{16}$ even the BMI rather poorly represents a person's percent of body fat. Despite all the criticisms, the Metropolitan Life Tables criteria for defining obesity were widely used in the United States until the early 1990s. ${ }^{22-24}$ At about that time, the World Health Organization (WHO) classification of body weight for height, based on the BMI, was published, ${ }^{25}$ and later it was widely adopted. ${ }^{26}$

\section{BMI Distribution in a Normal Population}

Although a BMI determination reduces the effect of lowerextremity length on the $\mathrm{Wt} / \mathrm{Ht}$ ratio, whether one uses the BMI or merely the ratio of weight to height, the population distribution is still not Gaussian. That is, it is not symmetrical but is always skewed to the right, that is, toward a higher ratio of weight (body mass) to height. For example, the distribution of BMIs in adult American men and women was determined in 1923 in 1026 individuals (Figure). ${ }^{27}$ The median BMI was 24, but the mean BMI was 25. The distribution curve clearly indicated a skewing toward an increase in BMI, and this trend has continued. ${ }^{26}$

This skewing is not surprising because a markedly reduced BMI, theoretically and actually, would be incompatible with life because of an excessive reduction in lean as well as fat mass as a result of under nutrition ${ }^{28}$ or disease. In contrast, excessive accumulation of body fat with maintenance or usually an increase in lean mass ${ }^{29,30}$ is at least compatible with life, even though it may eventually affect long-term survival.

\section{WHO and the Categorization of BMls Into Quartiles} In 1993, the WHO assembled an Expert Consultation Group with a charge of developing uniform categories of the BMI. The results were published as a technical report in $1995 .{ }^{25}$ Four categories were established: underweight, normal, overweight, and obese. An individual would be considered to be underweight if his/her BMI was in the range of 15 to 19.9, normal weight if the BMI was 20 to 24.9, overweight if the BMI was 25 to 29.9, and obese if it was 30 to 35 or greater. Using linear regression, a BMI of 16.9 in men and 13.7 in women represents a complete absence of body fat stores. ${ }^{31}$ The above 4 categories are similar to those suggested by John $\mathrm{S}$. Garrow in 1981, ${ }^{31,32}$ but the terminology was changed. The terminology he used was "desirable" for a BMI up to 25, "grade I obesity" between 25 and 29.9, "grade II obesity," between 30 and 40, and "grade III obesity" for BMI greater than 40. The latter classification was based on Rosenbaum and colleagues ${ }^{33}$ own data obtained in a survey of an adult population, aged 16 to 64 years, in Great Britain and published in 1985. The population-based data indicated the majority of people were in the "desirable" range of the BMI distribution as indicated in Table 1. Unfortunately, this distribution is not and has not been similar to those found in other surveys. The BMIs have been higher.

At the time that the WHO classification was published, the National Institutes of Health (NIH) in the United States classified people with a BMI of 27.8 (men) and 27.3 (women)

\begin{tabular}{|l|c|c|c|c|}
\hline TABLE 1 & Garrow Classification \\
\hline & Desirable & Grade I & Grade II & Grade III \\
\hline BMI & (Up to 25) & $(25-29.9)$ & $(30-40)$ & $(\geq 40)$ \\
\hline \multicolumn{5}{|c|}{ Percentage } \\
\hline Women & 67.6 & 24 & 8 & 0.4 \\
\hline Men & 58.2 & 34 & 6 & 0.2 \\
\hline Abbreviation: BMI, body mass index \\
\hline
\end{tabular}


or greater as being overweight. If they were below this BMI, they were considered to be "normal." This was based on an $85 \%$ cutoff point of people examined in the National Health and Nutrition Examination Study (NHANES) II. ${ }^{12,22,34}$ Subsequently, in 1998, the cutoff point between normal and overweight was reduced to a BMI of 25 to bring it into line with the 4 categories in the WHO guidelines. ${ }^{25,35}$ Parenthetically, this instantaneously converted millions of Americans from being "normal weight" to being "overweight."

In 1997, the International Obesity Task Force expanded the number of BMI categories to include different degrees of obesity and changed the terminology modestly. ${ }^{36} \mathrm{~A}$ BMI of 25 to 29.9 is referred as "preobesity," a BMI of 30 to 34.9 is class I obesity, 34.9 to 39.9 is class II obesity, and a BMI of 40 or greater is class III obesity. ${ }^{37,38}$

The new terminology appears to be a bit presumptuous and careless because the BMI is not a direct measure of percent of fat mass, and the dynamic concept that those in the former "overweight" category are now in the "preobesity" category invariably going on to "obesity" is not the case. Also those with a lower BMI initially, but with a dynamic weight gain over time, would have to transition through this category in order to become classified as "obese" regardless of the terminology. By analogy, should those classified as "underweight" now be referred to as being "prenormal"?

\section{Distribution of BMI in the General Population}

It should be understood that in Western population-based studies, generally the mean or median BMI is about 24 to $27 .^{22,27,39,40}$ Thus, the consequence of adopting the WHO classification is that $\sim 50 \%$ or more of the general adult population will always be in the overweight (now preobese) and obese categories. Indeed, the term "overweight" or particularly "preobesity" is prejudicial since people in this category are a major part of the expected normal distribution of BMI in the general population, and this has been the case for decades. Unfortunately, in discussing the so-called "obesity epidemic," the number of people in the overweight (preobese) category generally is lumped together with those in the obese category in order to advertise and dramatize the perceived seriousness of this issue.

Regardless of the terminology and population reference issues, at present the BMI is the currency by which we define the obesity issue throughout the Western world. It was developed for the convenience of the epidemiologists, and indeed it did provide a uniform codification of body weight for height reporting. The BMI categories are shown in (Table 2).

\section{BMI as a Determinant of Body Fat Mass}

A particular problem with BMI as an index of obesity is that it does not differentiate between body lean mass and body fat mass; that is, a person can have a high BMI but still have a very low fat mass and vice versa. ${ }^{39,41-46}$

\begin{tabular}{|l|c|}
\hline TABLE 2 Categories of BMI \\
\hline Underweight & $15-19.9$ \\
\hline Normal weight & $20-24.9$ \\
\hline Overweight & $25-29.9$ \\
\hline Preobesity \\
\hline Class I obesity \\
\hline Class II obesity & $30-34.9$ \\
\hline Class III obesity & $35-39.9$ \\
\hline Abbreviation: BMI, body mass index \\
\hline
\end{tabular}

From an anatomical and metabolic perspective, the term obesity should refer to an excessive accumulation of body fat (triacylglycerols), and upon these grounds, the accuracy of the BMI as a determinant of body fat mass has been repeatedly questioned, ${ }^{16,39-41,46-48}$ because it clearly has limitations in this regard. Gender, age, ethnic group, and leg length are important variables. ${ }^{45,49-55}$ It should be noted that in population-based studies women generally have a BMI that is lower than that in men, even though their fat mass relative to their body build or BMI is considerably greater ( 20\% to $45 \%+)$.

The relatively poor correlation between percent of body fat mass and BMI in males has been known for many years ${ }^{16}$ and was clearly shown in a study in which percent of body fat was determined by a densitometric method. ${ }^{56}$ For men with a BMI of 27 in that study, the $95 \%$ confidence intervals for percent of body fat were $10 \%$ to $32 \%$; that is, in this group, the percent of body fat varied from very little to that considered to be in the obesity range. (NIH-suggested criterion for obesity based on percent of body fat for men is $\geq 25 \%$, and that for women is $\geq 35 \% .{ }^{57}$ ) The relatively poor correlation between percent of body fat mass and BMI also clearly has been shown more recently in the NHANES III database in which bioelectrical impedance was used to estimate the fat component of body composition. ${ }^{51}$ In subjects with a BMI of $25 \mathrm{~kg} / \mathrm{m}^{2}$, the percent of body fat in men varied between $14 \%$ and $35 \%$, and in women it varied between $26 \%$ and $43 \%$. Thus, using the NIH-suggested criterion based on percent of body fat to define obesity, subjects with a BMI of 25 , a group that would be considered to be essentially normal, were associated with a body fat mass that varied again between low normal to obese. Also it is of interest that in the entire NHANES cohort, the BMI correlated better with lean body mass than with fat mass in men. ${ }^{51}$ More recent NHANES data also indicate a poor correlation of BMI with percent of body fat, particularly in men. ${ }^{58}$

In addition, in a recent study in individuals with or without diabetes in which the loss of lean body mass with aging 
was reported, the mean $\mathrm{BMI}$ in those without diabetes was 26.8. In those with diabetes, the BMI was 29.1; that is, it was higher as generally expected. However, the percent of lean body mass was the same; that is, the increased BMI in those with diabetes was not due only to an excessive accumulation of fat. ${ }^{59}$

\section{Trends in Body Weight and Height}

Over the past several decades, there has been an increase in BMI in the general population. This has resulted in predictions of a public health disaster. It should be recognized that in the United States during the period from 1960 to 2002 not only has the mean weight increased by $24 \mathrm{lb}$ among men aged 20 to 74 years, but also the height has increased by about 1 in. We can then calculate that the weight increase per year has only been $0.57 \mathrm{lb}$, and as indicated above, this could be due to an increase in lean mass rather than fat mass, or it may be a combination of the two. In women, there was a similar increase in weight and height. ${ }^{40}$ In an earlier report, life-insured men up to age 40 years were reported to be 0.5 to 1.5 inches taller and 2 to $9 \mathrm{lb}$ heavier for the same height in 1959 than those studied 50 to 60 years prior to 1959 . Also, in the earlier study, the mortality rate was lowest in those with higher weight-to-height ratios. This was attributed to the presence in the population of wasting diseases such as tuberculosis that resulted in an increased death rate. ${ }^{13}$ Previously, a secular upward trend in height in adults in the United Kingdom also was reported. ${ }^{60}$ In addition, in a twin study in the United Kingdom, children in 2005 were not only heavier but also taller than 1990 norms, whereas their BMIs were essentially the same. ${ }^{3}$ Overall, the history of changes in height and weight in Western European men and probably women has been that of an increase in both weight and height. In the 17th century, the average height of men in Northern Europe was $\sim 5 \mathrm{ft} 3$ in. It now approaches $6 \mathrm{ft} .{ }^{61}$ These data suggest that the BMI categories should be adjusted upward periodically to accommodate population-based changes. Improvements in mortality rates also suggest an adjustment would be useful.

\section{Body Fat Location}

An additional limitation of the BMI is it does not capture body fat location information. This is an important variable in assessing the metabolic as well as mortality consequences of excessive fat accumulation. It was first recognized in France by Dr Jon Vague ${ }^{62}$ in the 1940-1950s. He noted that accumulation of fat in the upper part of the body versus the lower part of the body was associated with an increased risk for coronary heart disease, diabetes, and also gallstones and gout. That is, individuals who accumulated excessive fat in the lower body segment were relatively spared from these complications. The body fat distribution was referred to as being "android" if it occurred in the upper body and "gynecoid" when it occurred in the lower segment of the body. This is because men tend to accumulate fat in the abdominal (upper body) area, whereas women tend to accumulate it in the peripelvic (gluteal) area and the thighs. A surrogate for this information has been to determine the abdominal circumference or an abdominal/hip circumference ratio. Subsequent data indicate that indeed the risk for development of diabetes and the so-called "metabolic syndrome," as well as coronary heart disease, is more strongly related to the accumulation of upper body fat than lower body fat in both sexes. ${ }^{63-67}$ That is, an android (male) distribution more closely predicts the development of the chronic diseases of aging than does the gynecoid (female) distribution.

More specifically, both visceral fat accumulation ${ }^{68,69}$ and an expanded girth have been associated with development of insulin resistance, diabetes, and risk for coronary heart disease and hypertension. ${ }^{63,64,70-74}$ Accumulation of fat in the abdominal area appears to correlate best with triacylglycerols accumulating in the liver and skeletal muscle. These may actually represent the pathogeneticially important metabolic consequences that result in insulin resistance and more directly correlate with development of the above adverse medical conditions. ${ }^{68,75,76}$ Incidentally, the relatively small accumulation of fat in these organs would not be detectible by BMI determinations, and they do not correlate simply with total body fat mass. ${ }^{75}$

\section{The Life Cycle and Location of Accumulated Fat} Prior to puberty, boys and girls tend to be lean and not much different in this regard. Girls tend to accumulate relatively large amounts of fat during and after puberty, particularly in the peripelvic and thigh region; boys do not. During and after puberty, boys accumulate a relatively large amount of lean mass (bone and muscle) but not fat mass. In both sexes, these changes are reflected in an increased BMI. With aging, both sexes tend to develop fat in the upper part of the body (circumferentially), that is, the middle-age spread. ${ }^{49,77-80}$ The reason for these changes in amount and distribution is not completely understood. Generally, it is considered to be due to hormonal changes. It is of some interest that accumulation of fat in the lower body at puberty in females is unique to humans, is not present in any of the great apes, and most likely is estrogen mediated. ${ }^{1}$

In a teleological sense, why this occurs, if due to estrogen, is uncertain. It could represent a means of maintaining body fat during pregnancy without an undue expansion in abdominal girth. It also may act as a counterbalance when women carry a child either during pregnancy or afterward. It also may be a space-filling fat site due to the relatively larger pelvis in postpubertal females. ${ }^{81}$ Overall, it may represent an adaptation to the human upright bipedal posture. In any event, it results in a lower center of gravity among 
women compared with men. Indeed, the lower body segment in females becomes $\sim 40 \%$ greater than in males (quoted in Singh, 1993), ${ }^{1}$ and it has strong sex-related overtones.

Not only is thigh fat greater in women than in men, but also women generally have a preponderance of slow-twitch fibers, whereas men have a preponderance of fast-twitch fibers in their quadriceps muscles, as do upper-body-obese women, ${ }^{82}$ suggesting either genetic or earlier developmental differentiation events. Could this be an adaptation for loadbearing versus speed as a group survival adaptation?

As indicated above, the accumulation of fat with aging in both sexes tends to occur in the truncal area and is associated with an increase in visceral fat. In women, this could be explained by a decrease in circulating estradiol, that is, a decreased estrogen/testosterone ratio associated with the menopause. (Again of some interest, it is only humans who have a defined menopause).

In men, with aging, there is a decrease in testosterone and a relative increase in estrogen, resulting in a decrease in the testosterone/estrogen ratio. ${ }^{83}$ Thus, in men, a change in sex hormone concentrations could possibly explain the increased accumulation of fat in general. However, why there is a preferential accumulation in the truncal location, that is, why they too develop an increase in visceral fat, is unclear. Clearly, location of fat in this area would help to maintain mobility. The latter could be of great importance in hunter-gatherer societies and in defense of the tribe. Perhaps the distribution is programmed by gender earlier in life.

In this regard, it should be recognized that the accumulation of fat in certain body areas as well as the total amount of fat accumulated has a strong genetic or at least a familial component that diminishes with age. $3,27,84,85$

\section{Methods of Estimating Body Fat Mass and Location of the Fat}

At present, simple, accurate methods for measuring percent of body fat and, in particular, body fat in different fat depots are not available. The indirect methods currently in use for estimating total percent of body fat include underwater weighing, an air displacement and density determination using a Bod Pod, a bioelectrical impedance analyzer, and a determination of the isotopically labeled water mass. In the past, determination of the total body radioactive potassium and thus metabolizing tissue mass have been used to estimate lean body mass, and by difference, the fat mass. ${ }^{86}$

Anthropometric determination of fat mass directly has been done using skin-fold thickness measured at various sites. ${ }^{87}$ A dual-energy x-ray absorptiometry (DEXA) scan, which provides a 3-dimensional picture of body organ densities, can be used for estimating total body fat. Its location also can be determined. Single computed tomography (CT) slices of the abdomen and thigh can be used to obtain 2 dimensions of those fat depots from which a 3-dimensional fat area can be reconstructed. This also can be done using magnetic resonance imaging, but magnetic resonance imaging is very expensive. One cannot do serial sections of the body using CT to determine fat mass because of the excess radiation associated with this procedure.

Because of their convenience, bioelectric impedance methods or DEXA scans are the most commonly used to estimate the amount and, with DEXA scans, the location of body fat depots. Estimates of abdominal and thigh fat depots also can be estimated using CT slices. ${ }^{52,72,88}$

All of the previously mentioned methods use certain assumptions in the calculation of body fat mass, and all are subject to potential error. Nevertheless, there are more specific methods of determining body fat mass than is the BMI. Important information regarding the location of the stored fat also can be determined with some methods.

It now is generally accepted that a relationship between BMI and mortality risk should be applied only to large populations. It should not be applied to an individual in an unqualified fashion. As indicated previously, there is the issue of being "overweight" versus "over fat." In addition, a segment of the population is now considered to be "fat" by any criteria but "fit" and not at risk for early mortality. ${ }^{74,75,89-91}$

\section{$\mathrm{BMI}$ and Morbidity and Mortality}

The BMI classification system currently is being widely used in population-based studies to assess the risk for mortality in the different categories of BMI. It also is being used in regard to specific etiologies for mortality risk. However, as with its use to estimate percent of body fat, it is a rather crude approach. Even when some comorbidities are considered, the correlation of mortality rates with BMI often does not take into consideration such factors as family history of diabetes, hypertension, coronary heart disease, metabolic syndrome, dyslipidemias, familial longevity or the family prevalence of carcinomas, and so on. Recently it has been reported that more than $50 \%$ of susceptibility to coronary artery disease is accounted for by genetic variants. ${ }^{92}$ Frequently, when correlations are made they also do not take into consideration a past as well as a current history of smoking, alcohol abuse, serious mental disorders or the duration of obesity, when in the life cycle it appeared, and whether the body weight is relatively stable or rapidly progressive, that is, type 1 or type 2 obesity. ${ }^{93,94}$ In most population-based studies, only the initial weight and/or BMI are given, even though weight as well as fat stores are known to increase and height to decrease with aging. In addition, the rate of weight gain varies among individuals, $7,94,95$ as does the loss of muscle mass. ${ }^{95}$ Muscle mass has been correlated negatively with insulin resistance and prediabetes. ${ }^{96}$ Lastly, population-based studies do not take into consideration the present and past history of a person's occupation, 
medication-induced obesity, and how comorbidities are being treated. All of the above are significant issues.

\section{More Explicit Problems in Relating the BMI to Medical Issues}

Based on data in the literature, there are several additional problems in determining associations between BMI and overall death rate or, more specifically, cardiovascular events or death rates. Many obese people do not have cardiovascular risk factors, and in those who do, BMI no longer correlates with cardiovascular events ${ }^{97-101}$ when the untoward effects of these other factors are factored out. Another issue is that the treatment status of the previously mentioned cardiovascular risk factors often is unknown or not stated; that is, the efficacy of treatment is rarely considered. This also is the case for diabetes. For example, the prevalence of diabetes has been increasing but not the disease-specific death rate. ${ }^{102}$ Also, in people with diabetes, the death rate from cardiovascular disease has decreased dramatically. ${ }^{102}$

\section{The "Obesity Epidemic"}

Recently, there has been concern that an epidemic of obesity is occurring, not only in the United States, but also worldwide based on BMI data. In the NHANES data, there has been a change in the mean but to a greater extent in the distribution of BMI for adults aged 20 to 74 years in the United States. ${ }^{26}$ That is, the mean BMI has increased, but there has been a greater increase in skewing toward the right and very large BMI. This results in more individuals being categorized as "obese." The reason for the recent increase in mean BMI, but particularly in those in the obese category, is unknown, although there are many speculations. The dramatic decrease in smoking is likely to have been a contributor. ${ }^{91,103-106}$ Smoking contributes to population-based BMI by at least 2 mechanisms. Smoking impairs appetite per se. It also is pathogenetically important in the development of chronic obstructive pulmonary disease, which itself results in a lower body mass. Of some interest, NHANES data also indicate that the trend of an increase in BMI has not continued since 1999 in women and only modestly in men. ${ }^{58}$ Smoking rates also have stabilized at a low level.

\section{Is Being "Overweight" by BMI Criteria a} Medical Issue?

Regardless of an observed increased skewing in the BMI distribution, it is important to note that several recent studies indicate that for most of us being a bit overweight (preobese?) as determined by BMI may not be so bad. ${ }^{107-111}$ The EPIC observational study is a population-based study that includes 359387 individuals aged 25 to 70 years living in Europe. ${ }^{109}$ The mean age of this group at the initiation of the study was 51.5 years, and the mean follow-up has been $9.7 \pm 2$ years. In this study, both the crude and ad- justed relative risk of death among men was actually the lowest in those with a BMI of 26.5 to 28 , that is, those in the overweight (preobese) category. Also, a significant increase in risk of death was present only among those with a BMI of less than 21 or greater than 30 . That is, there is a wide range of BMIs in the central part of this population in which there was relatively little impact of BMI on risk of death over a 9.7-year period.

Similar data were obtained in the NIH-American Association of Retired Persons study of 527265 men and women between the ages of 50 and 71 years in the United States and followed for up to 10 years. ${ }^{110}$ The lowest death rate in the entire cohort was among those in the "overweight" category, and this was particularly true among the men. There also was a broad range of BMIs over which there was little difference in mortality (BMI of 23.5 to 30).

The NHANES data going back to 1971 and up to 1994 also indicate that the relative mortality risk is lowest in men with a BMI of 25 to 30 in all age groups, that is, from the age of 25 years up to the age of 70 years. ${ }^{107}$ In addition, the risk of mortality was little affected by a BMI from 18.5 up to a $\mathrm{BMI}$ of 30 in all age categories. Indeed, in those older than 70 years, there was little impact on the death rate even if they were in the obese category. Similar results have been reported for women in the NHANES reports. ${ }^{112}$ The lowest mortality occurred with a BMI of 27.

In a Canadian study, the age-adjusted mortality rate over 13 years in men was essentially unchanged in those with a BMI of 18.5 up to 35 , that is, from the Normal Weight category through the obesity class I category. In women, there was only a modest increase over the same range. ${ }^{113}$ In summary, there is a large range of BMIs over which there is little association with the death rate. Generally, the range is from a BMI of 21 up to and often including 30. It is centered in the 24-to-28 BMI range. This information is not entirely new. Andres ${ }^{114}$ in 1980 summarized 16 different population-based studies in which anthropometrically determined obesity was not associated with increased mortality rate. A detailed analysis in 1960 of the Metropolitan Life Insurance data also suggested little increase in mortality rates in people with a degree of overweight less than $20 \%$ or more above the average for a given height and age (quoted in Keys et $\mathrm{al}^{97}$ ).

Interestingly, in the EPIC observational Study, ${ }^{109}$ when the waist circumference-to-BMI ratio was calculated, that is, adjusting the waist circumference for BMI, it tended to linearize the association of BMI with risk for death, and the ratio was greatest for those with a low BMI. Thus, even if an individual had a low BMI but a relatively increased waist circumference, the risk was increased. Indeed, for any given BMI, a 5 -cm increase in circumference increased the risk of death by a factor of 1.17 among men and 1.13 for women. Also in this study, the overall greatest mortality risk was in those individuals with the lowest BMI and not 
those with the highest BMI. Nevertheless, even in the category with the lowest BMI, adjusting for waist circumference affected the mortality rate negatively. This again indicates the importance of the location of body fat in addition to the total amount of fat accumulated.

A recent analysis of 50 prospective observational studies indicated the lowest mortality at a BMI of 23 to 25. However, these data were obtained in the 1970s and 1980s in an aggregate population with a mean BMI of 24.8, that is, lower than at present. The increased mortality at higher BMI's was modest up to a BMI of 27.5, and the authors could account for the excess mortality largely on the risk factors known to be associated with obesity. The latter are currently being much better treated than in that era. ${ }^{115}$

\section{Issues to be Resolved When Relating BMI With Health Determinants}

Overall, a major unresolved issue is which factor of the following is more important in the prediction of comorbidities such as cardiovascular disease, diabetes, hypertension, malignancies, or overall death rates. Is it BMI, total body fat mass, or the distribution of body fat, that is, visceral versus subcutaneous, or upper body fat accumulation (as determined by abdominal circumference, or a waist/hip ratio, or some combination of these, and so on)? The EPIC ${ }^{109}$ data suggest that where fat is accumulated is much more important than merely the BMI, with the exception of those with an exceeding large total fat mass.

\section{SUMMARY AND GONGLUSION}

It is time to move beyond the BMI as a surrogate for determining body fat mass. Alternatively, if BMI continues to be used, the categories and definitions should be changed to reflect the current distribution of BMIs in the general population.

A better means than the BMI for estimating percent of body fat and its relationship to mortality and various morbidities clearly would be desirable.

The BMI was not originally developed for use specifically as an index of fatness in population-based studies. However, it has been coopted for this use because it is a readily obtained metric. It should be understood that the BMI has serious limitations when used as an indicator of percent of body fat mass. Indeed, it may be misleading in this regard, particularly in men. The terminology currently used also is prejudicial. By definition, one-half or more adults in the recent past and currently are overweight (preobese) or obese in Western, industrialized nations.

The current BMI classification system also is misleading in regard to effects of body fat mass on mortality rates. The role of fat distribution in the prediction of medically significant morbidities as well as for mortality risk is not captured by use of the BMI. Also, numerous comorbidities, lifestyle issues, gender, ethnicities, medically significant familial-determined mortality effectors, duration of time one spends in certain BMI categories, and the expected accumulation of fat with aging are likely to significantly affect interpretation of BMI data, particularly in regard to morbidity and mortality rates. Such confounders as well as the known clustering of obesity in families, the strong role of genetic factors in the development of obesity, the location in which excessive fat accumulates, its role in the development of type 2 diabetes and hypertension, and so on, need to be considered before promulgation of public health policies that are designed to apply to the general population and are based on BMI data alone.

Clearly, obesity, as determined by BMI, is not a monotypic, age-invariant condition requiring a general public health "preventative" approach. A BMI-determined categorization of an individual should not be used exclusively in counseling or in the design of a treatment regimen. In addition, when considering weight loss regimens, variations in body weight attributed to weight loss and dietary cycling may be hazardous. ${ }^{116-120}$ They have been associated with an increased mortality rate. ${ }^{116,117,119,121-124}$ The concept of starvation-associated obesity ${ }^{125,126}$ also needs to be considered.

\section{Prevention and/or Treatment of BMI-Determined Overweight or Obesity}

Clearly episodic starvation or semistarvation regimens are not the answer, ${ }^{127}$ nor are population-based efforts to increase fresh fruits and vegetables and tax soda pop, and so on. In my opinion, the major focus on prevention and treatment should be on those unfortunate individuals who are grossly obese, mechanically compromised, and who are at very high risk for death. ${ }^{128}$ Surgical gastrointestinal intervention has proven to be at least partially successful in improving fuel regulation and storage. ${ }^{129,130}$ Hopefully, medications will be developed that will reinstitute a metabolic fuel regulatory system that prevents the relentless accumulation of body fat, which is characteristic of those who are grossly obese. For others, an improvement in physical fitness may be salutary.

\section{A Personal Perspective Regarding the Obesity Epidemic}

Currently there are 4 truths regarding historical changes in body weights and the prevalence of obesity. People of Western European extraction are on average (1) heavier, (2) taller, and (3) more likely to be "overweight" or "obese" as defined by current BMI standards than those in other parts of the world. However, (4) it also should be pointed out they are healthier and are living longer than in any previous period in history. ${ }^{131,132}$

Beginning in the 17 th century, ${ }^{61}$ the general underlying theme in all the studies done on weight gain in populations is an increase in height as well as weight. These changes are likely to be due to an increase in high-quality dietary 
protein (animal products), as well as an increased availability of total food energy in the diet. That is, there was not only an increase in food availability and variety, but also an increase in food quality. ${ }^{133}$ The near elimination of chronic and serious acute infectious diseases also may have played a role, as has the dramatic decrease in cigarette smoking and its serious medical consequences.

The net effect of the above is that the chronic diseases of aging have become more of a public health problem, but better treatments are widely available. The prevalence of type 2 diabetes has increased, but overall the cardiovascular death rate has decreased dramatically. The death rate from malignancies is decreasing, and there has been a remarkable improvement in longevity, which is continuing. ${ }^{131}$ The latter also is likely to continue into the future. ${ }^{131,132}$ Some view the secular trend in the US population over the past 40 years as being one in which the population in general is "more obese, more diabetic, more arthritic, more disabled, and more medicated" but living longer. ${ }^{134} \mathrm{~A}$ less sanguine view is indicated by others. ${ }^{135}$ Many consider the overabundance of "calorie dense, processed foods," the availability of soda pop, ${ }^{136}$ and presence of fast-food restaurants and large food portion sizes to be strong, pathogenetic, obesity-inducing factors, ${ }^{137}$ or more broadly, they consider obesity to be due to a "toxic" or "poisonous" food supply. ${ }^{138}$ Some also are concerned that the increase in obesity (defined by BMI) will overwhelm any gains in health and life expectancy noted over the past several decades, that is, an Apocalypse awaits us. ${ }^{139}$ I and others ${ }^{140,141}$ do not share this pessimism.

Finally, I would like the political activists and doomsday prophets whose professional careers appear to depend on frightening the public and inducing politicians to pass restrictive laws without proven value, to be introduced to the prescient comments made by A. E. Harper ${ }^{133} 33$ years ago. It is clear that currently we have a case of "déjà vu all over again."

In regard to predicting the future, a wise person whose name I cannot recall stated presciently "Predicting the future is a fool's playground"; the physicist Neils Bohr said, "Prediction is very difficult, especially about the future," or as stated by that sage of the baseball world, Yogi Berra, "The future ain't what it used to be." Bertrand Russell said, "Fools and fanatics are always so sure of themselves, but wiser people are so full of doubt." The true scientist should always be a skeptic.

\section{Acknowledgments}

The author thanks Rachel Anderson for help in preparing the manuscript for submission and Dr Mary C. Gannon for reading the manuscript and making numerous helpful comments.

\section{REFERENCES}

1. Singh D. Body shape and women's attractiveness: the critical role of waist-to-hip ratio. Human Nature. 1993;4(3):297-321.

2. Katzmarzyk PT, Perusse L, Rao DC, Bouchard C. Familial risk of overweight and obesity in the Canadian population using the WHO/NIH criteria. Obes Res. 2000;8(2):194-197.

3. Wardle J, Carnell S, Haworth CM, Plomin R. Evidence for a strong genetic influence on childhood adiposity despite the force of the obesogenic environment. Am J Clin Nutr. 2008; 87(2):398-404

4. Katzmarzyk PT, Hebebrand J, Bouchard C. Spousal resemblance in the Canadian population: implications for the obesity epidemic. Int J Obes Relat Metab Disord. 2002;26(2):241-246.

5. Rogers O. Build as a Factor Influencing Longevity. In Proceedings of the Association of Life Insurance Medical Directors of America from Organization to and including the 10th annual meeting: 12th annual meeting held at the Hunt Memorial Building of the Hartford Medical Society; May 29, 1901; Hartford, CT New York: Knickerbocker Press; 1901:280-288.

6. The Association of Life Insurance Medical Directors and the Actuarial Society of America. Medico-Actuarial Mortality Investigation. Vol 1-3. New York, NY: 1912-1913.

7. Metropolitan Life Insurance Company. New weight standards for men and women. Stat Bull. 1959;40:1-4.

8. Metropolitan Life Insurance Company. Mortality record for 1959. Stat Bull. 1960;41(February):1-11.

9. Metropolitan Life Insurance Company. Mortality among overweight women. Stat Bull. 1960;41(March):1-11.

10. Metropolitan Life Insurance Company. 1983 Metropolitan height and weight tables for men and women, according to frame, ages 25-29. Stat Bull. 1983;64(Jan-June):2-9.

11. Burton BT, Foster WR, Hirsch J, Van Itallie TB. Health implications of obesity: an NIH Consensus Development Conference. Int J Obes. 1985;9(3):155-170.

12. Health implications of obesity. National Institutes of Health Consensus Development Conference; February 11-13, 1985. Ann Intern Med. 1985;103(6 (pt 2)):977-1077.

13. Blackburn H, Parlin RW. Antecedents of disease. Insurance mortality experience. Ann N Y Acad Sci. 1966;134:965-1017.

14. Khosla T, Lowe CR. Indices of obesity derived from body weight and height. BrJ Prev Soc Med. 1967;21(3):122-128.

15. Himes JH, Bouchard C. Do the new Metropolitan Life Insurance weight-height tables correctly assess body frame and body fat relationships? Am J Public Health. 1985;75(9):1076-1079.

16. Keys A, Fidanza F, Karvonen MJ, Kimura N, Taylor HL. Indices of relative weight and obesity. J Chron Dis. 1972;25(6):329-343.

17. Watson PE, Watson ID, Batt RD. Obesity indices. Am J Clin Nutr. 1979;32(4):736-737.

18. Benn RT. Some mathematical properties of weight-for-height indices used as measures of adiposity. Br J Prev Soc Med. 1971;25(1):42-50.

19. Eknoyan G. Adolphe Quetelet (1796-1874) — the average man and indices of obesity. Nephrol Dial Transplant. 2008;23(1):47-51.

20. Quetelet LAJ. Physique Sociale. Vol 2. Brussels, Belgium: C. Muquardt; 1869:92.

21. Jelliffe DB, Jelliffe EF. Underappreciated pioneers. Quetelet: man and index. Am J Clin Nutr. 1979;32(12):2519-2521.

22. Kuczmarski RJ, Flegal KM, Campbell SM, Johnson CL. Increasing prevalence of overweight among US adults. The National Health and Nutrition Examination Surveys, 1960 to 1991. JAMA. 1994;272(3):205-211.

23. Manson JE, Stampfer MJ, Hennekens CH, Willett WC. Body weight and longevity. A reassessment. JAMA. 1987;257(3):353-358.

24. Must A, Dallal GE, Dietz WH. Reference data for obesity: 85 th and 95th percentiles of body mass index (wt/ht2) and triceps skinfold thickness. Am J Clin Nutr. 1991;53(4):839-846.

25. WHO. Physical Status: The Use and Interpretation of Anthropometry: Report of a World Health Organization (WHO) Expert Committee. Geneva, Switzerland: World Health Organization; 1995.

26. Flegal KM, Carroll MD, Kuczmarski RJ, Johnson CL. Overweight and obesity in the United States: prevalence and trends, 1960-1994. Int J Obes Relat Metab Disord. 1998;22(1):39-47. 
27. Rony H. The homeostatic body weight regulation. Obesity and Leanness. Philadelphia, PA: Lea \& Febiger; 1940:192-209.

28. Leiter LA, Marliss EB. Survival during fasting may depend on fat as well as protein stores. JAMA. 1982;248(18):2306-2307.

29. Salans LB, Horton ES, Sims EA. Experimental obesity in man: cellular character of the adipose tissue. J Clin Invest. 1971;50(5):1005-1011.

30. Forbes GB, Welle SL. Lean body mass in obesity. Int J Obes. 1983;7(2):99-107.

31. Garrow JS, Webster J. Quetelet's index (W/H2) as a measure of fatness. Int J Obes. 1985;9(2):147-153.

32. Garrow JS. Treat Obesity Seriously: A Clinical Manual. Edinburgh, Scotland: Churchill Livingstone; 1981

33. Rosenbaum S, Skinner RK, Knight IB, Garrow JS. A survey of heights and weights of adults in Great Britain, 1980. Ann Hum Biol. 1985;12(2):115-127.

34. Najjar MF, Rowland M. Anthropometric reference data and prevalence of overweight, United States, 1976-80. Vital Health Stat 11. 1987;(238):1-73.

35. National Institutes of Health, National Heart, Lung, and Blood Institute. Clinical Guidelines on the Identification, Evaluation, and Treatment of Overweight and Obesity in Adults: The Evidence Report. Bethesda, MD: National Institutes of Health; 1998.

36. WHO. Managing the global epidemic of obesity. Report of the World Health Organization (WHO) consultation on obesity. Paper presented at the International Obesity Task Force June 3-5, 1997; Geneva, Switzerland.

37. International Obesity Task Force. Managing the Global Epidemic of Obesity. Report of the World Health Organization (WHO) Consultation on Obesity; June 5-7, 1997; Geneva, Switzerland.

38. WHO. Obesity: Preventing and Managing the Global Epidemic. Geneva, Switzerland: WHO; 2000

39. Wellens RI, Roche AF, Khamis HJ, Jackson AS, Pollock ML, Siervogel RM. Relationships between the body mass index and body composition. Obes Res. 1996;4(1):35-44.

40. Ogden CL, Fryar CD, Carroll MD, Flegal KM. Mean body weight, height, and body mass index, United States 1960-2002. Adv Data. 2004;(347):1-17.

41. Strain GW, Zumoff B. The relationship of weight-height indices of obesity to body fat content. J Am Coll Nutr. 1992;11(6):715-718.

42. Segal KR, Dunaif A, Gutin B, Albu J, Nyman A, Pi-Sunyer FX Body composition, not body weight, is related to cardiovascular disease risk factors and sex hormone levels in men. $J$ Clin Invest. 1987;80(4):1050-1055.

43. Romero-Corral A, Somers VK, Sierra-Johnson J, et al. Normal weight obesity: a risk factor for cardiometabolic dysregulation and cardiovascular mortality. Eur Heart J. 2010;31(6):737-746.

44. Garn SM, LaVelle M, Rosenberg KR, Hawthorne VM. Maturational timing as a factor in female fatness and obesity. Am J Clin Nutr. 1986;43(6):879-883.

45. Norgan NG. Relative sitting height and the interpretation of the body mass index. Ann Hum Biol. 1994;21(1):79-82.

46. Flegal KM, Shepherd JA, Looker AC, et al. Comparisons of percentage body fat, body mass index, waist circumference, and waist-stature ratio in adults. Am J Clin Nutr. 2009;89(2):500-508.

47. Garn SM, Leonard WR, Hawthorne VM. Three limitations of the body mass index. Am J Clin Nutr. 1986;44(6):996-997.

48. Heitmann BL, Erikson H, Ellsinger BM, Mikkelsen KL, Larsson B. Mortality associated with body fat, fat-free mass and body mass index among 60-year-old swedish men-a 22-year follow-up. The study of men born in 1913. Int J Obes Relat Metab Disord. 2000;24(1):33-37.

49. Borkan GA, Hults DE, Gerzof SG, Robbins AH, Silbert CK. Age changes in body composition revealed by computed tomography. J Gerontol. 1983;38(6):673-677.

50. Kuczmarski RJ. Prevalence of overweight and weight gain in the United States. Am J Clin Nutr. 1992;55(Suppl 2):495S-502S

51. Romero-Corral A, Somers VK, Sierra-Johnson J, et al. Accuracy of body mass index in diagnosing obesity in the adult general population. Int J Obes (Lond). 2008;32(6):959-966.
52. Rice CL, Cunningham DA, Paterson DH, Lefcoe MS. Arm and leg composition determined by computed tomography in young and elderly men. Clin Physiol. 1989;9(3):207-220.

53. Appropriate body-mass index for Asian populations and its implications for policy and intervention strategies. Lancet. 2004;363:157-163.

54. Deurenberg P, Yap M, van Staveren WA. Body mass index and percent body fat: a meta analysis among different ethnic groups. Int J Obes Relat Metab Disord. 1998;22(12):1164-1171.

55. Wang J, Thornton JC, Russell M, Burastero S, Heymsfield S, Pierson RN Jr. Asians have lower body mass index (BMI) but higher percent body fat than do whites: comparisons of anthropometric measurements. Am J Clin Nutr. 1994;60(1):23-28.

56. Smalley KJ, Knerr AN, Kendrick ZV, Colliver JA, Owen OE. Reassessment of body mass indices. Am J Clin Nutr. 1990; 52(3):405-408.

57. National Institutes of Health. Understanding Adult Obesity Bethesda, MD: National Institutes of Health; 2008.

58. Flegal KM, Carroll MD, Ogden CL, Curtin LR. Prevalence and trends in obesity among US adults, 1999-2008. JAMA20;303(3): 235-241.

59. Park SW, Goodpaster BH, Lee JS, et al. Excessive loss of skeletal muscle mass in older adults with type 2 diabetes. Diabetes Care. 2009;32(11):1993-1997.

60. Morant GM. A discussion on the measurement of growth and form; secular changes in the heights of British people. Proc $R$ Soc Lond B Biol Sci. 1950;137(889):443-452.

61. Fogel RW. The Escape From Hunger and Premature Death, 1700-2100. Cambridge, UK: The Press Syndicate of the University of Cambridge; 2004

62. Vague J. The degree of masculine differentiation of obesities: a factor determining predisposition to diabetes, atherosclerosis, gout, and uric calculous disease. Am J Clin Nutr. 1956;4(1):20-34.

63. Kissebah AH, Freedman DS, Peiris AN. Health risks of obesity. Med Clin North Am. 1989;73(1):111-138.

64. Kissebah AH, Vydelingum N, Murray R, et al. Relation of body fat distribution to metabolic complications of obesity. J Clin Endocrinol Metab. 1982;54(2):254-260.

65. Ohlson LO, Larsson B, Svardsudd K, et al. The influence of body fat distribution on the incidence of diabetes mellitus. 13.5 years of follow-up of the participants in the study of men born in 1913. Diabetes. 1985;34(10):1055-1058.

66. Lapidus L, Bengtsson C, Larsson B, Pennert K, Rybo E, Sjostrom L. Distribution of adipose tissue and risk of cardiovascular disease and death: a 12 year follow up of participants in the population study of women in Gothenburg, Sweden. Br Med J (Clin Res Ed). 1984;289(6454):1257-1261

67. Fox KA, Despres JP, Richard AJ, Brette S, Deanfield JE. Does abdominal obesity have a similar impact on cardiovascular disease and diabetes? A study of 91,246 ambulant patients in 27 European countries. Eur Heart J. 2009;30(24):3055-3063.

68. Wajchenberg BL, Giannella-Neto D, da Silva ME, Santos RF. Depot-specific hormonal characteristics of subcutaneous and visceral adipose tissue and their relation to the metabolic syndrome. Horm Metab Res. 2002;34(11-12):616-621.

69. Nguyen-Duy TB, Nichaman MZ, Church TS, Blair SN, Ross R Visceral fat and liver fat are independent predictors of metabolic risk factors in men. Am J Physiol Endocrinol Metab. 2003;284(6):E1065-E1071

70. Despres JP, Moorjani S, Lupien PJ, Tremblay A, Nadeau A, Bouchard C. Regional distribution of body fat, plasma lipoproteins, and cardiovascular disease. Arteriosclerosis. 1990;10(4): 497-511.

71. Pouliot MC, Despres JP, Lemieux S, et al. Waist circumference and abdominal sagittal diameter: best simple anthropometric indexes of abdominal visceral adipose tissue accumulation and related cardiovascular risk in men and women. Am J Cardiol. 1994;73(7):460-468. 
72. Pouliot MC, Despres JP, Nadeau A, et al. Associations between regional body fat distribution, fasting plasma free fatty acid levels and glucose tolerance in premenopausal women. Int J Obes. 1990;14(4):293-302.

73. Lemieux S, Prud'homme D, Tremblay A, Bouchard C, Despres JP. Anthropometric correlates to changes in visceral adipose tissue over 7 years in women. Int J Obes Relat Metab Disord. 1996; 20(7):618-624.

74. Wildman RP, Muntner P, Reynolds K, et al. The obese without cardiometabolic risk factor clustering and the normal weight with cardiometabolic risk factor clustering: prevalence and correlates of 2 phenotypes among the US population (NHANES 1999-2004). Arch Intern Med. 2008;168(15):1617-1624.

75. Stefan N, Kantartzis K, Machann J, et al. Identification and characterization of metabolically benign obesity in humans. Arch Intern Med. 2008;168(15):1609-1616.

76. Savage DB, Petersen KF, Shulman GI. Disordered lipid metabolism and the pathogenesis of insulin resistance. Physiol Rev. 2007;87(2):507-520.

77. Lemieux S, Prud'homme D, Bouchard C, Tremblay A, Despres JP. A single threshold value of waist girth identifies normal-weight and overweight subjects with excess visceral adipose tissue. $\mathrm{Am}$ J Clin Nutr. 1996;64(5):685-693.

78. Lemieux S, Prud'homme D, Nadeau A, Tremblay A, Bouchard C, Despres JP. Seven-year changes in body fat and visceral adipose tissue in women. Association with indexes of plasma glucoseinsulin homeostasis. Diabetes Care. 1996;19(9):983-991.

79. Toth MJ, Tchernof A, Sites CK, Poehlman ET. Effect of menopausal status on body composition and abdominal fat distribution. Int J Obes Relat Metab Disord. 2000;24(2):226-231.

80. Skerlj B. Age changes in fat distribution in the female body. Acta Anat (Basel). 1959;38:56-63.

81. Tanner JM. Growth at Adolescence. Oxford: Blackwell Scientific Publications; 1955.

82. Bjorntorp P. The android woman - a risky condition. J Intern Med. 1996;239(2):105-110.

83. Davidson JM, Chen JJ, Crapo L, Gray GD, Greenleaf WJ, Catania JA. Hormonal changes and sexual function in aging men. J Clin Endocrinol Metab. 1983;57(1):71-77.

84. Malis C, Rasmussen EL, Poulsen P, et al. Total and regional fat distribution is strongly influenced by genetic factors in young and elderly twins. Obes Res. 2005;13(12):2139-2145.

85. Bouchard C, Despres JP, Mauriege P. Genetic and nongenetic determinants of regional fat distribution. Endocr Rev. 1993; 14(1):72-93.

86. Larsson I, Lindroos AK, Peltonen M, Sjostrom L. Potassium per kilogram fat-free mass and total body potassium: predictions from sex, age, and anthropometry. Am J Physiol Endocrinol Metab. 2003;284(2):E416-E423.

87. Garn SM. Anthropometry in clinical appraisal of nutritional status. Am J Clin Nutr. 1962;11:418-432.

88. Borkan GA, Hults DE, Gerzof SG, Robbins AH. Comparison of body composition in middle-aged and elderly males using computed tomography. Am J Phys Anthropol. 1985;66(3):289-295.

89. Sims EA. Are there persons who are obese, but metabolically healthy? Metabolism. 2001;50(12):1499-1504.

90. Ruderman NB, Schneider SH, Berchtold P. The "metabolicallyobese," normal-weight individual. Am J Clin Nutr. 1981;34(8): 1617-1621.

91. Pisinger C, Jorgensen T. Waist circumference and weight following smoking cessation in a general population: the Inter 99 study. Prev Med. 2007;44(4):290-295.

92. McPherson R. Chromosome 9p21 and coronary artery disease. N Engl J Med. 2010;362(18):1736-1737.

93. Nuttall FQ. Diet and the diabetic patient. Diab Care. 1983; 6:197-207.

94. Chaudhry ZW, Gannon MC, Nuttall FQ. Stability of body weight in type 2 diabetes. Diabetes Care. 2006;29(3):493-497.
95. Forbes GB, Reina JC. Adult lean body mass declines with age: some longitudinal observations. Metabolism. 1970;19:653-663.

96. Srikanthan P, Karlamangla AS. Relative muscle mass is inversely associated with insulin resistance and prediabetes. Findings from the third National Health and Nutrition Examination Survey. J Clin Endocrinol Metab. 2011;96(9):2898-2903.

97. Keys A, Aravanis C, Blackburn H, et al. Coronary heart disease: overweight and obesity as risk factors. Ann Intern Med. 1972; $77(1): 15-27$.

98. Chapman JM, Massey FJ Jr. The interrelationship of serum cholesterol, hypertension, body weight, and risk of coronary disease. results of the first ten years' follow-up in the Los Angeles Heart Study. J Chron Dis. 1964;17:933-949.

99. Kip KE, Marroquin OC, Kelley DE, et al. Clinical importance of obesity versus the metabolic syndrome in cardiovascular risk in women: a report from the Women's Ischemia Syndrome Evaluation (WISE) study. Circulation. 2004;109(6):706-713.

100. St-Pierre AC, Cantin B, Mauriege P, et al. Insulin resistance syndrome, body mass index and the risk of ischemic heart disease. CMAJ. 2005;172(10):1301-1305.

101. Keys A. Overweight and the risk of sudden heart attack and sudden death NIH; 1973:215-223.

102. Preis SR, Pencina MJ, Hwang SJ, et al. Trends in cardiovascular disease risk factors in individuals with and without diabetes mellitus in the Framingham Heart Study. Circulation. 2009;120(3): 212-220.

103. Filozof C, Fernandez Pinilla MC, Fernandez-Cruz A. Smoking cessation and weight gain. Obes Rev. 2004;5(2):95-103.

104. Flegal KM. The effects of changes in smoking prevalence on obesity prevalence in the United States. Am J Public Health. 2007;97(8):1510-1514.

105. Yeh HC, Duncan BB, Schmidt MI, Wang NY, Brancati FL. Smoking, smoking cessation, and risk for type 2 diabetes mellitus: a cohort study. Ann Intern Med5;152(1):10-17.

106. O'Hara P, Connett JE, Lee WW, Nides M, Murray R, Wise R. Early and late weight gain following smoking cessation in the Lung Health Study. Am J Epidemiol. 1998;148(9):821-830.

107. Flegal KM, Graubard BI, Williamson DF, Gail MH. Excess deaths associated with underweight, overweight, and obesity. JAMA. 2005;293(15):1861-1867.

108. Romero-Corral A, Montori VM, Somers VK, et al. Association of bodyweight with total mortality and with cardiovascular events in coronary artery disease: a systematic review of cohort studies. Lancet. 2006;368(9536):666-678.

109. Pischon T, Boeing H, Hoffmann K, et al. General and abdominal adiposity and risk of death in Europe. $N$ Engl J Med. 2008;359(20):2105-2120

110. Adams KF, Schatzkin A, Harris TB, et al. Overweight, obesity, and mortality in a large prospective cohort of persons 50 to 71 years old. N Engl J Med. 2006;355(8):763-778.

111. Troiano RP, Frongillo EA Jr, Sobal J, Levitsky DA. The relationship between body weight and mortality: a quantitative analysis of combined information from existing studies. Int J Obes Relat Metab Disord. 1996;20(1):63-75.

112. Zhu S, Heo M, Plankey M, Faith MS, Allison DB. Associations of body mass index and anthropometric indicators of fat mass and fat free mass with all-cause mortality among women in the first and second National Health and Nutrition Examination Surveys follow-up studies. Ann Epidemiol. 2003;13(4):286-293.

113. Katzmarzyk PT, Craig CL, Bouchard C. Original article underweight, overweight and obesity: relationships with mortality in the 13-year follow-up of the Canada Fitness Survey. J Clin Epidemiol. 2001;54(9):916-920.

114. Andres R. Effect of obesity on total mortality. Int J Obes. 1980; 4(4):381-386

115. Whitlock G, Lewington S, Sherliker P, et al. Body-mass index and cause-specific mortality in 900000 adults: collaborative analyses of 57 prospective studies. Lancet. 2009;373(9669):1083-1096. 
116. National Task Force on the Prevention and Treatment of Obesity. Weight cycling. JAMA. 1994;272(15):1196-1202.

117. Gaesser GA. Thinness and weight loss: beneficial or detrimental to longevity? Med Sci Sports Exerc. 1999;31(8):1118-1128.

118. National Task Force on the Prevention and Treatment of Obesity. Weight cycling. JAMA. 1994;272(15):1196-1201.

119. Danforth E Jr, Sims EA. Obesity and efforts to lose weight N Engl J Med. 1992;327(27):1947-1948.

120. Hamm P, Shekelle RB, Stamler J. Large fluctuations in body weight during young adulthood and twenty-five-year risk of coronary death in men. Am J Epidemiol. 1989;129(2):312-318.

121. Lissner L, Odell PM, D'Agostino RB, et al. Variability of body weight and health outcomes in the Framingham population. N Engl J Med. 1991;324(26):1839-1844.

122. Gregg EW, Gerzoff RB, Thompson TJ, Williamson DF. Trying to lose weight, losing weight, and 9-year mortality in overweight U.S. adults with diabetes. Diabetes Care. 2004;27(3): 657-662.

123. Sorensen TI, Rissanen A, Korkeila M, Kaprio J. Intention to lose weight, weight changes, and 18-y mortality in overweight individuals without co-morbidities. PLoS Med. 2005;2(6):e171.

124. Blair SN, Shaten J, Brownell K, Collins G, Lissner L. Body weight change, all-cause mortality, and cause-specific mortality in the Multiple Risk Factor Intervention Trial. Ann Intern Med. 1993;119(7 Pt 2):749-757.

125. Dulloo AG. Human pattern of food intake and fuel-partitioning during weight recovery after starvation: a theory of autoregulation of body composition. Proc Nutr Soc. 1997;56(1A): 25-40.

126. Keys A, Brozek J, Henshel O, Mickleson O, Taylor HL. The Biology of Human Starvation. Minneapolis, MN: University of Minnesota Press; 1950.

127. Mann T, Tomiyama AJ, Westling E, Lew AM, Samuels B, Chatman J. Medicare's search for effective obesity treatments: diets are not the answer. Am Psychol. 2007;62(3):220-233.

128. Drenick EJ, Bale GS, Seltzer F, Johnson DG. Excessive mortality and causes of death in morbidly obese men.JAMA. 1980;243(5): 443-445.

129. Sjostrom L, Narbro K, Sjostrom CD, et al. Effects of bariatric surgery on mortality in Swedish obese subjects. N Engl J Med. 2007;357(8):741-752.

130. Shah M, Simha V, Garg A. Review: long-term impact of bariatric surgery on body weight, comorbidities, and nutritional status. J Clin Endocrinol Metab. 2006;91(11):4223-4231.

131. National Center for Health Statistics. Health, United States, 2009: In Brief. Hyattsville, MD; 2010. http://www.cdc.gov/nchs/data/hus/ hus09_InBrief.pdf. Accessed April 28, 2015.

132. Rodu B, Cole P. We're living longer healthier lives. St Paul Pioneer Press. January 30, 2007.

133. Harper AE. Dietary goals - a skeptical view. Am J Clin Nutr. 1978;31:310-321.

134. Gregg EW, Cheng YJ, Cadwell BL, et al. Secular trends in cardiovascular disease risk factors according to body mass index in US adults. JAMA. 2005;293(15):1868-1874.

135. Kim S, Popkin BM. Commentary: understanding the epidemiology of overweight and obesity - a real global public health concern. Int J Epidemiol. 2006;35(1):60-67 discussion 62-81.

136. Brownell KD, Farley T, Willett WC, et al. The public health and economic benefits of taxing sugar-sweetened beverages. N Engl J Med. 2009;361(16):1599-1605.

137. Nestle M, Jacobson MF. Halting the obesity epidemic: a public health policy approach. Public Health Rep. 2000;115(1):12-24.

138. Battle EK, Brownell KD. Confronting a rising tide of eating disorders and obesity: treatment vs. prevention and policy. Addict Behav. 1996;21(6):755-765.

139. Olshansky SJ, Passaro DJ, Hershow RC, et al. A potential decline in life expectancy in the United States in the 21st century. N Engl J Med. 2005;352(11):1138-1145.

140. Preston SH. Deadweight? The influence of obesity on longevity. $N$ Engl J Med. 2005;352(11):1135-1137.

141. Couzin-Frankel J. A pitched battle over life span. Science. 29; 333(6042):549-550.

\section{Evidence-Based Approach to Fiber Supplements and Clinically Meaningful Health Benefits, Parts 1 and 2: What to Look for and How to Recommend an Effective Fiber Therapy: Erratum}

The articles cited above, published in the March/April 2015 issue of Nutrition Today, were designated for open access but were not identified as such in the print issue. Open access labels have been applied and the articles are freely available on the journal's Web site: www.nutritiontodayonline.com.

\section{References}

1. McRorie JW. Evidence-based approach to fiber supplements and clinically meaningful health benefits, part 1: what to look for and how to recommend an effective fiber therapy. Nutr Today. 2015;50(2): 82-89.

2. McRorie JW. Evidence-based approach to fiber supplements and clinically meaningful health benefits, part 2: what to look for and how to recommend an effective fiber therapy. Nutr Today. 2015;50(2):90-97.

DOI: 10.1097/NT.0000000000000100 